\title{
A Review Paper on PAPR Reduction Techniques using Clipping\& Filtering, Selective Mapping and Companding Methods in OFDM Systems
}

\author{
Okello Kenneth ${ }^{1}$, Professor Usha Neelakanta ${ }^{2}$ \\ P.G. Student, Department of Electronics \& Telecommunication Engineering, Ahmedabad Gujarat, India ${ }^{1}$ \\ Department of Electronics \& Telecommunication Engineering, Ahmedabad Gujarat, India ${ }^{2}$
}

\begin{abstract}
Due to overlapping of the subcarrier, OFDM system promotes transmission of high data rates, spectral efficiency, spectrum flexibility, and resistance against intercarrier interference \& InterSymbol interference by using guard interval without using equalizer. This lead OFDM to perform many applications including, Digital Video Broadcasting-Terrestrial, Digital Audio Broadcasting, Military HF radio links, Asymmetric Digital Subscriber line and Broadband radio access networks. In spite of the wonderfulness of OFDM, one extraordinary disadvantage is PAPR which degrade its performance, and lower the Bit error rate (BER). This drawback can be eliminated by using some tremendous reduction methods including, clipping \& filtering, companding, Selective mapping, Tone injection, Tone reservation, Partial transmission sequences, etc.
\end{abstract}

Keywords: PAPR, OFDM, PTS, SLM etc.

\section{INTRODUCTION}

OFDM is the most significant mean of communication over channels with different frequency component signal experiencing different fading level due to its multipath. Multiple carriers due to high data rate transmission are used to overcome it problem of OFDM. This technology is mainly used in a $4 \mathrm{G}$ cellular standard, i.e. long term evolution (LTE), long term evolution advanced (LTEA),Worldwide interoproperbility for microwave access(Wi-MAX) and Wireless fidelity (Wi-Fi) or wireless local area network (WLAN) such as 802.11a $802.11 \mathrm{~g}, 802.11 \mathrm{n}, 802.11 \mathrm{ac}$ which are IEEE dominant standard which enable high data rate of about $100 \mathrm{Mbs}$ basing on OFDM.

The idea behind OFDM is that its single carrier is placed at the centre of the bandwidth of the carrier frequency with a total bandwidth and it divides the frequency spectrum into sub-carriers which are made mutually independent to each other by using inverse fast Fourier transform (IFFT) for the multi-carrier modulated signal which performs the transformation data information very effectively and provides a simple way of ensuring the carrier signals produced are orthogonal at the transmitter. The Fast Fourier Transform (FFT) transforms a cyclic time domain signal into its equivalent frequency spectrum at the receiver.

In OFDM the presence of delay dispersion may cause InterSymbol interference (ISI) a form of distortion in which one signal interferes with another signal and intercarrier interference (ICI) due to the presence of Doppler shift, frequency and phase offset which cause OFDM signal to lose it orthogonality. Cyclic prefix is done to remove the problem of interference, i.e. removing the last part of the signal and adding to the front and later remove from the receiver before demodulation.

\section{A. Mathematical representation of OFDM signal}

In OFDM system, let consider $\mathrm{N}$ data block represented by vectorX $=\left[\begin{array}{lllll}X_{0} X_{1} X_{2} & \ldots & \ldots & \ldots & X_{N-1}\end{array}\right]^{T}$ information symbol loaded onto the subcarrier symbol. $\mathrm{T}$ is the symbol period. The baseband representation of original OFDM symbol can be formulated as per equation (1)

$$
\mathrm{x}(\mathrm{k})=\frac{1}{\mathrm{~N}} \sum_{\mathrm{n}=0}^{\mathrm{N}-1} \mathrm{X}_{\mathrm{i}} \mathrm{e}^{\mathrm{j} 2 \pi \mathrm{i} \Delta \mathrm{ft}} 0 \leq \mathrm{t} \leq \mathrm{T}
$$

Where

$\mathrm{x}(\mathrm{k})$ Is the $\mathrm{k}^{\text {th }}$ IFFT information sample

$\mathrm{X}_{\mathrm{i}}$ Collection of information symbol at the transmitter

$\Delta \mathrm{f}$ Sub-carrier frequency spacing

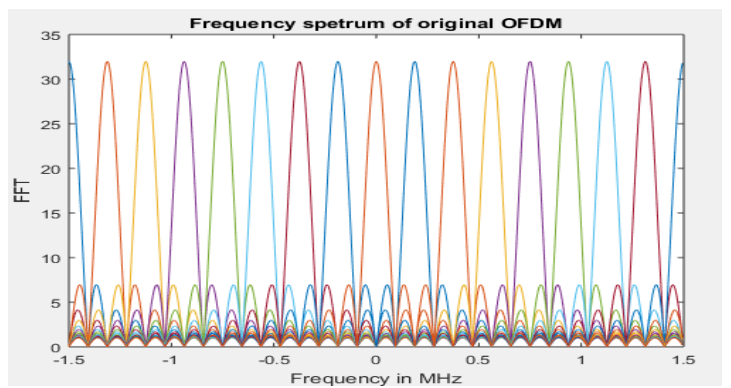

Fig. 1.1 Frequency spectrum of baseband OFDM system

\section{PEAK TO AVERAGE POWER RATIO (PAPR)}

The PAPR describe the momentary power emitted from the OFDM transmitter. This can be seen that power of the transmitter is characterized by relatively low average and 
high peak power. In OFDM the PAPR is in the magnitude of $10 \mathrm{~dB}$ depending on the number of each subcarrier and modulation used. The average probability to have power of relatively $10 \mathrm{~dB}$ is high leading to high battery consumption

The peak to average power ratio (PAPR) of a continuous time signal is given by equation (2)

$$
\mathrm{PAPR}=\frac{\mathrm{P}_{\text {Peak }}}{\mathrm{p}_{\text {Average }}}=\frac{\left.\max \mathrm{|x}(\mathrm{k})\right|^{2}}{\left.\mathrm{E} \mathrm{x}(\mathrm{k})\right|^{2}} .
$$

And discrete time signal equation (3).

$$
\mathrm{PAPR}=\frac{\max |\mathrm{x}(\mathrm{n})|^{2}}{\mathrm{E}|\mathrm{x}(\mathrm{n})|^{2}}
$$

Where

E: denotes the expected value

$\mathrm{x}(\mathrm{n})$ or $\mathrm{x}(\mathrm{k})$ :denote the transmitted OFDM signals

$\mathrm{P}_{\text {Peak }}$ : denote peak value

$\mathrm{p}_{\text {Average }}$ :is the average output power

$\mathrm{N}$ subcarrier

Hence PAPR of the OFDM system rises with increase in the number of subcarrier $\mathrm{N}$. so PAPR is the major drawback of OFDM system and some PAPR reduction equations are discuss below.

The threshold value is calculated from the equation (4) below

$$
\text { Threshold }=\left(\frac{\mathrm{PAPR}_{\max }-\mathrm{PAPR}_{\text {min }}}{\mathrm{PAPR}_{\max } \mathrm{PAPR}_{\text {min }}}\right)
$$

The Complementary Cumulative Distribution Function (CCDF) of the PAPR is one of the most frequently used methods to check how often the PAPR exceed the threshold values. Graph is plotted among threshold and CCDF values. The CCDF can be calculated by using the relation

$$
\begin{gathered}
\breve{\mathrm{F}}_{\mathrm{PAPR}_{\text {max }}}\left(\mathrm{PAPR}_{0}\right)=\mathrm{P}\left(\mathrm{PAPR}_{\text {max }}<\mathrm{PAPR}_{0}\right) \\
\breve{\mathrm{F}}_{\mathrm{PAPR}_{\text {max }}}\left(\mathrm{PAPR}_{0}\right)=1-\mathrm{P}\left(\mathrm{PAPR}_{\max }<\mathrm{PAPR}_{0}\right) \\
\breve{\mathrm{F}}_{\mathrm{PAPR}_{\text {max }}}\left(\mathrm{PAPR}_{0}\right)=1-\mathrm{F}_{\mathrm{PAPR}_{\max }}\left(\mathrm{PAPR}_{0}\right)^{\mathrm{N}} \\
\left(\mathrm{PAPR}>\mathrm{P}_{0}\right)=1-\left(1-\mathrm{e}^{-\mathrm{P}_{0}}\right)^{\mathrm{N}} \ldots \ldots \ldots \ldots(5)
\end{gathered}
$$

\section{REDUCTION TECHNIQUES}

Numerous techniques approach have been proposed to reduce Peak to Average Power Ratio (PAPR) which fall in two categories i.e. distortion and distortionless. Distortion techniques include clipping and companding whereas distortionless correspond to selective mapping, clipping \& filtering, partial transmit sequence, tone reservation and tone injection and many more.

\section{A. Partial transmit sequence}

PTS is the modernized method of selective mapping where the original OFDM is divided into a set of sub block and the phase sequence rotation are added to select the one with the lowest PAPR for transmission.

\section{B. Tone reservation}

This method depends upon the reserve tone, location within the frequency vector and the amount of the complexity of PAPR reduction. The smaller the reserve tone high reduction is experiencing at the transmitter with low complexity at the receiver, whereas high reserve tone leads to low reduction of PAPR at the transmitter with high complexity in the receiver is observed. Undertone reservation no side information is required to be sent to the receiver in order for determination of the source of information since all the data is submitted at once.

\section{Selective mapping}

SLM is the most effective method in the reduction of PAPR where a set of OFDM symbolis generated for agiven transmitted system and lastly the one candidature with the lowest PAPR is selected for automatic transmission. In generally when considering the block diagram of selective mapping, $U$ phase sequence is produce from the same data source which helps us to generate the lowest PAPR. The idea is that the phase sequence will change PAPR of transmitted data vector, $B(U)=\left[b_{u, 0} b_{u, 1} \ldots . . b_{u, N-1}\right]^{T}$ which is multiple, with independent phase sequence $P(U)=\left[P_{0} b_{u, 0} P_{1} b_{u, 1} \ldots . P_{N-1} b_{u, N-1}\right]^{T}(\mathrm{u}=1,2,3 \ldots . \mathrm{U}$, where $U$ is the phase sequence, both the input data and phase sequence have the same length. Information about the selected phase sequence $\log _{2} U$ should be transmitted to the receiver as 'side information

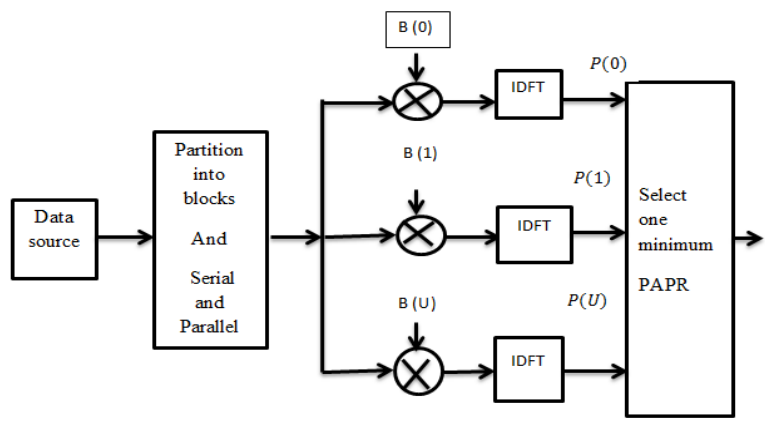

Fig.2.1The illustration block diagram of selective mapping Statistically independent is consider for each mapping, the CCDF of PAPR will be

$$
\left(P A P R>P_{0}\right)=\left(1-\left(1-e^{-P_{0}}\right)^{N}\right)^{U}
$$

Where:

$\mathrm{U}$ is the number of phase sequence

$P_{0}$ Is the threshold level

$\mathrm{N}$ is the number of the subcarrier.

We also based on "Nee and Prasad" proposal which show equivalent approximation, this explain the probability of PAPR by $\mathrm{N}$ subcarriers approximately and oversampling distribution of $\alpha$. Oversampling with $\alpha=2.8$ give the best value to reach better PAPR when subcarriers $N>64$. These Oversampling is needed because the PAPR of digital signal is not the same as the PAPR of the analogy signal. The approximation is shown below

$$
\left(P A P R>P_{0}\right)=\left(1-\left(1-e^{-P_{0}}\right)^{\alpha \cdot N}\right)^{U}
$$

\section{Clipping and filtering}

Under this method,parts of a given signal are clip. This caused in band distortion and out of band radiation leading to peak regrowth, increase bit error rate (BER), and lower 
spectral efficiency whereas the out of band radiation can be reduced by filtering hence lower PAPR.

In clipping, over sampling is necessary because the PAPR of the digital signal is not the same as PAPR of the analogy signal. And due to over sampling of the PAPR, there is always problem of inbound distortion and out of bound radiation which cause spectral leakages. This cause can be filtered to suppress the peak regrowth by carryingiterative clipping and filtering. For each iteration requires two inverse fast Fourier transform and one extra IFFT is required to convert the clipped OFDM symbol to time domainafter the last iteration. As we know that the Kiteration process requires approximate $(2 \mathrm{~K}+1) \mathrm{FFT} / \mathrm{IFFT}$, the by increasing the number of iterations simply implies increasing the computational complexity of the signal, increasing Bit error rate (BER) especially when large subcarriers number are used. The following equation shows the amplitude clipping.

$$
Y(t)=\left\{\begin{array}{c}
-A \quad \text { if } x(t)<-A \\
x(t) \text { if }-A \leq x(t) \leq A \\
A \quad \text { if } x(t)>A
\end{array}\right.
$$

Where:

A is the clipping level,

$x(t)$ Is the original transmitted signal

$Y(t)$ Is the clipped signal

\section{E. Companding}

Companding compresses of two methods, compression, which is performed at the transmitter immediately after IFFT and expansion at the receiver preliminary in the FFT process used. Under this $\mu$-law compressor is used at the transmitter and $\mu$-law expander at the receiver and later $A$ -law companding is used to control the amount of compression hence lowering the PAPR. One tremendous merits of companding is to preserve the signal to noise ratio of the audio. These two methods $\mu$-law compressor and $A$-law companding [Jianping Wang]. In this dissertation, A-law companding is used

\section{1. $\mu$-Law companding.}

The $\mu$-law compander employs the logarithmic function at the transmitting side. In general a $\mu$ - law compression characteristic:

$$
Y=\left\{V \log _{e}\left(1+\frac{\mu|X|}{V}\right) / \log _{e}(1+\mu)\right\} \operatorname{sgn} \text {. }
$$

\section{Where}

$\mu$ : is the $\mu$-law parameter of the compander, parameter that controls the amount of compression. The maximum value of output $\mathrm{y}$ is the same maximum of input $\mathrm{x}$ is equal $\mathrm{v}$. $\mathrm{X}$ : input signal: is the maximum value of the signal $\mathrm{x}$ Normalized input signal with $|\mathrm{x}| \leq 1$,

A-law Companding

The characteristic of this compander is given by: $Y=\frac{1+\operatorname{In} A|X|}{1+\operatorname{In} A}(\operatorname{sgn}(X))$....

A: parameter controls the amount of compression.

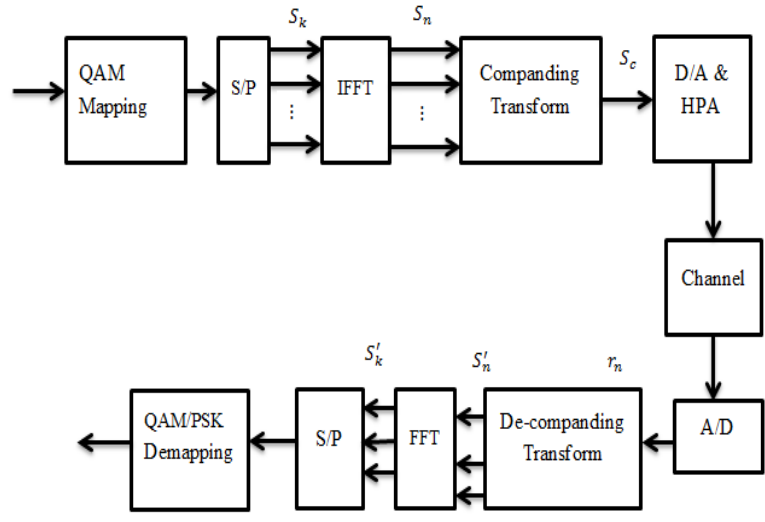

Fig.2.2 Block diagram of Companding techniques

\section{EXPECTED RESULTS}

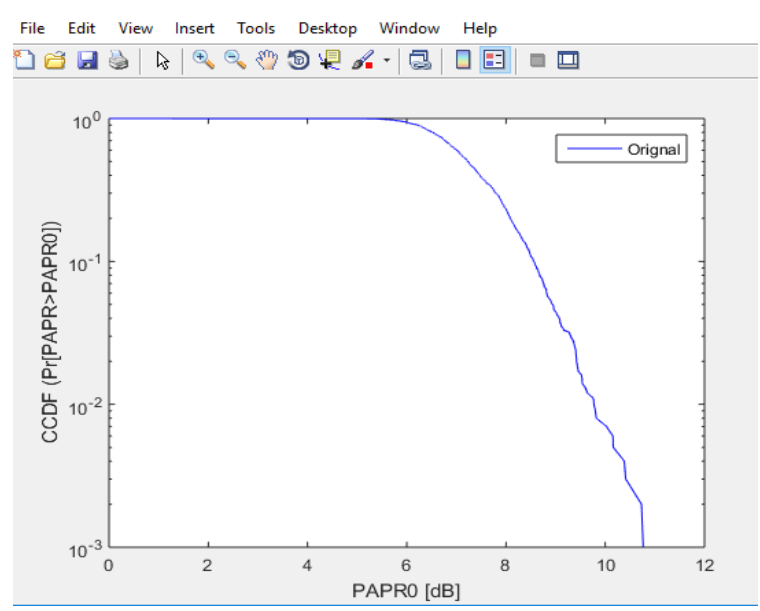

Fig.3.1CCDF of a normal OFDM system

Initially, it is necessary to know the performance of the normal OFDM before applying any reduction techniques to reduce the peak power level. As we know that PAPR level depends on the number of the subcarriers meaning the PAPR is equal to the normal OFDM symbol. From the above figure, we approximately the OFDM level to be $10.9 \mathrm{~dB}$ when 128 subcarriers are used.

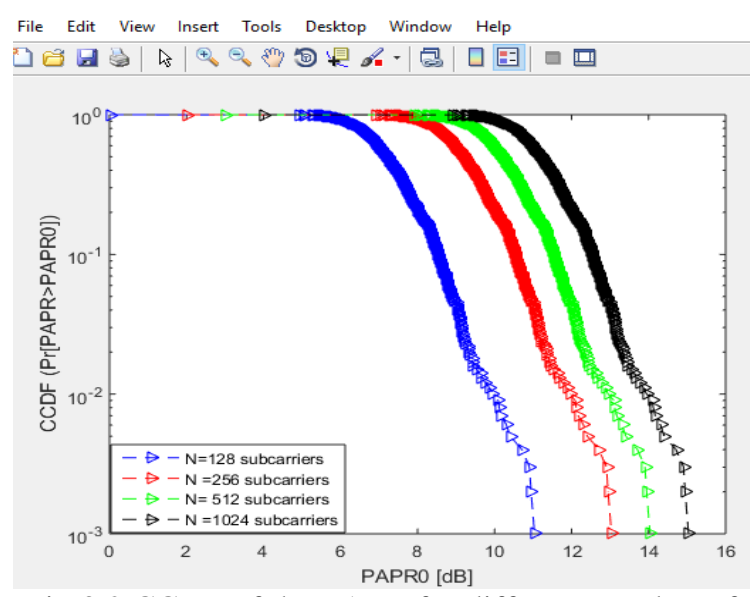

Fig.3.2 CCDF of the PAPR for different number of subcarriers 
As we see from the graph, on increasing the number of subcarriers PAPR increases, meaning that that the peak power depends on the number of subcarrier for any OFDM signal transmission in any system. This means that its BER increases with increase in the number of subcarrier.

As we see from the graph above, by using modern clipping and filtering, the PAPR reduction is seen to be approximately $7.0 \mathrm{~dB}$ lower than the normal PAPR of about $11.0 \mathrm{~dB}$ with a difference of about $4.0 \mathrm{~dB}$. Hence, by using one time clipping and filtering we experience a lower reduction as we shall see in much iteration techniques.

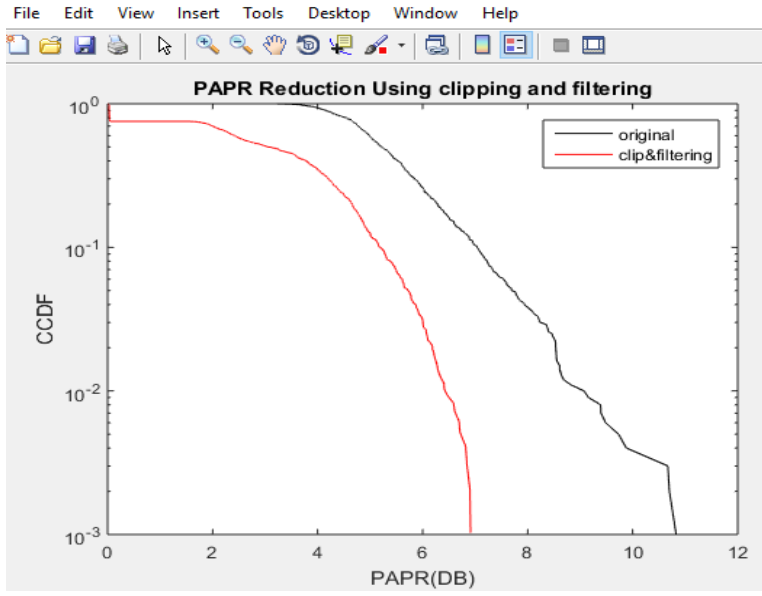

Fig.3.3 Original PAPR for Clipping and filtering

\section{COMPARISON OF ALL THE TECHNIQUES}

\begin{tabular}{|c|c|c|c|c|}
\hline \multirow{2}{*}{$\begin{array}{l}\text { Reduction } \\
\text { techniques }\end{array}$} & \multicolumn{3}{|c|}{ Parameters } & \multirow{2}{*}{$\begin{array}{l}\text { Operation required at transmitters }(\mathrm{TX}) \\
\text { and receiver }(\mathrm{RX})\end{array}$} \\
\hline & $\begin{array}{l}\text { Decrease } \\
\text { distortion }\end{array}$ & $\begin{array}{l}\text { Power } \\
\text { raise }\end{array}$ & $\begin{array}{l}\text { Defeat Data } \\
\text { rate }\end{array}$ & \\
\hline $\begin{array}{l}\text { Clipping and Filtering } \\
(\mathrm{C} \& \mathrm{~F})\end{array}$ & No & No & No & $\begin{array}{l}\text { TX: Clipping } \\
\text { RX: None }\end{array}$ \\
\hline $\begin{array}{l}\text { Selective Mapping } \\
\text { (SLM) }\end{array}$ & Yes & No & Yes & $\begin{array}{l}\text { TX:M times IDFTs operations } \\
\text { RX: Side information extraction inverse } \\
\text { SLM }\end{array}$ \\
\hline $\begin{array}{l}\text { Partial transmit } \\
\text { sequence (PTS) }\end{array}$ & Yes & No & Yes & $\begin{array}{l}\text { TX: V times IDFTs operations } \\
\text { RX: Side information extraction inverse PTS }\end{array}$ \\
\hline Companding & No & No & No & $\begin{array}{l}\text { TX: Compressing } \\
\text { RX: Expanding }\end{array}$ \\
\hline Tone Injection (TI) & Yes & Yes & Yes & None \\
\hline Tone & Yes & No & No & None \\
\hline
\end{tabular}

\section{CONCLUSIONS}

In this paper, we compare all the above mentioned reduction techniques on PAPR of OFDM system and generally we found out that all the methods reduce the peak power with less complexity, good bit error rate (BER) though other technique cause any interference, other have multi efficient power reduction. We used different modulation techniques like QAM, QPSK, and 16PSK to analysis their performance.

\section{REFERENCES}

[1] S. H. Han and J. H. Lee, "An overview of peak-to-average power ratio reduction techniques for multicarrier transmission", IEEE Wireless Comm, vol. 12, no.2, pp.56-65, Apr. 2005.

[2] Sanjeev Saini and Dr. O.P. Sahu, "Peak to Average Power Ratio Reduction in OFDM System by Clipping and Filtering", International Journal of Electronics Communication and Computer Technology (IJECCT) Volume 2 Issue 3, May 2012

[3] R.W.Bauml, R.F.H.Fischer, and J.B. Huber, "Reducing the peak-toaverage power ratio of multi carrier modulation by selective mapping," IEE Electron. Lett. vol.32, pp. 20562057, Oct. 1996.

[4] J. M. Cioffi, EE379a lecture notes at Stanford University, Jan. 2006 "Tone Injection with Hexagonal Constellation for Peak-to-Average Power Ratio Reduction in OFDMS. M. Metev and V. P. Veiko,
Laser Assisted Micro technology, 2nd ed., R. M. Osgood, Jr. Ed. Berlin, Germany: Springer-Verlag, 1998.

[5] Ohkubo, N. and Ohtsuki, T. (Apr. 2003) Design criteria for phase sequences in selected mapping.IEEE VTC'03, vol. 1, pp. 373-377.

[6] Tao Jiang, Member IEEE, and Yiyan Wu, Fellow, IEEE, "An Overview: Peak-to-Average Power Ratio Reduction Techniques for OFDM Signals" VOL. 54, NO. 2, 2008

[7] Tellambura, C. (1998) A coding technique for reducing peak-toaverage power ratio in OFDM. IEEE GLOBECOM'98, vol. 5, pp. 2783-2787.

[8] Pankaj Kumar Sharma," Power Efficiency Improvement in OFDM System using SLM with Adaptive Nonlinear Estimator" World Applied Sciences Journal 7 (Special Issue of Computer \&IT): 145151, 2009, ISSN 1818.4952

[9] Pooria Varahram, Borhanuddin Mohd Ali "'Analysing the effects of peak to average power ratio and digital predistortion in orthogonal frequency division multiplexing (OFDM) systems", Scientific Research and Essays Vol. 6(10), pp. 2195-2200, 18 May, 2011

[10] Sanjeev Saini and Dr. O.P. Sahu, "Peak to Average Power Ratio Reduction in OFDM System by Clipping and Filtering", International Journal of Electronics Communication and Computer Technology (IJECCT) Volume 2 Issue 3, May 2012. 